\title{
Operative treatment for femoral shaft nonunions, a systematic review of the literature
}

\author{
Matthijs P. Somford • Michel P. J. van den Bekerom • \\ Peter Kloen
}

Received: 20 January 2013/Accepted: 20 July 2013/Published online: 27 July 2013

(C) The Author(s) 2013. This article is published with open access at Springerlink.com

\begin{abstract}
The objective of this article is to systematically review the currently available literature to formulate evidence-based guidelines for the treatment of femoral shaft nonunions for clinical practice and to establish recommendations for future research. Articles from PubMed/ MEDLINE, Cochrane Clinical Trial Register, and EMBASE, that presented data concerning treatment of nonunions of femoral shaft fractures in adult humans, were included for data extraction and analysis. The search was restricted to articles from January 1970 to March 2011 written in the English, German, or Dutch languages. Articles containing data that were thought to have been presented previously were used once. Reports on nonunion after periprosthetic fractures, review articles, expert opinions, abstracts from scientific meetings, and case reports on 5 or fewer patients were excluded. The data that were extracted from the relevant articles included: type of nonunion, type of initial and secondary treatments, follow-up,
\end{abstract}

Presented as a poster at the national congress on trauma in Holland: Traumadagen 2011.

M. P. Somford $(\bowtie) \cdot$ P. Kloen

Department of Orthopaedic Surgery, Academic Medical Centre,

Meibergdreef 15, P.O. Box 22660, 1105 AZ Amsterdam,

The Netherlands

e-mail: mp_somford@hotmail.com

P. Kloen

e-mail: P.kloen@amc.uva.nl

M. P. J. van den Bekerom

OLVG, Amsterdam, The Netherlands

e-mail: Bekerom@gmail.com union rate, and general complications. Most studies had different inclusion criteria and outcome measures, thus prohibiting a proper meta-analysis. Therefore, only the union rate and number of complications were compared between the different treatments. Methodological quality was assessed by assigning levels of evidence as previously defined by the Centre for Evidence-Based Medicine. This systematic review provides evidence in favour of plating if a nail is the first treatment; after failed plate fixation, nailing has a $96 \%$ union rate. After failed nailing, augmentative plating results in a $96 \%$ union rate compared to $73 \%$ in the exchange nailing group.

Keywords Nonunion - Pseudarthrosis - Review · Femur

\section{Introduction}

Since the introduction of intramedullary (IM) nails around 1939 by Küntscher, the treatment of long bone fractures has dramatically changed [1]. When Küntscher's technique became known worldwide, 500 patients had already been treated with this method, mostly soldiers [2].

Since then, several studies have provided data which seem to favour reamed over unreamed nailing to decrease the risk of developing a nonunion in the primary treatment, but nevertheless this specific issue remains under debate [3, 4]. In the case of a nonunion, however, there is little evidence for the optimal treatment.

The objective of this article is to systematically review the currently available literature to formulate evidencebased guidelines for the treatment of femoral shaft nonunions for clinical practice and to establish recommendations for future research. 
Table 1 Search query used in this systematic review, including the limits

(("Femoral Fractures"[Mesh]) OR (femur AND fracture*) OR (femoral AND fracture*)) AND (midshaft OR shaft OR diaphyseal) AND (ununited OR union delay OR Fracture Healing OR pseudarthrosis OR delayed union* OR delayed union OR nonunion* OR nonunion* OR nonunion*)

Limits: Humans, English, German, Dutch, All adult: $19+$ years

Nonunion definition

The US Food and Drugs Administration (FDA) defines a nonunion as a fractured bone that has not completely healed within 9 months of injury and that has not shown progression towards healing over 3 consecutive months on serial radiographs [5]. The exact time frame likely differs per fractured bone and location within the bone, soft tissue condition, and fracture type.

Radiographically, a nonunion is defined by the presence of the following criteria: absence of bone trabeculae crossing the fracture site, sclerotic fracture edges, persistent fracture lines, and lack of progressive change towards union on serial radiographs. The presence or absence of callus is not a criterium since this depends on the site of the fracture, and whether there is primary or secondary bone healing involved. Furthermore, there should be persistent pain, or even motion at the fracture site. This is best elicited by weight bearing.

The objective of this article is to systematically review the currently available literature to formulate evidencebased guidelines for treatment of femoral shaft nonunions for clinical practice and recommendations for future research.

\section{Materials and methods}

Inclusion and exclusion criteria

All titles and abstracts of relevant studies were reviewed with a set of predefined inclusion and exclusion criteria. All articles from January 1970 onward that presented data concerning treatment of nonunions of femoral shaft fractures were included for further data extraction. In general, a delayed union is defined as no fracture healing after 6 months and nonunion is defined a no fracture healing after 9 months with no radiological progression for 3 consecutive months. The definition of a nonunion or delayed union differed per article, and sometimes no time until diagnosis of a nonunion was provided. All primary and delayed/nonunion treatments were included. Septic and aseptic nonunions were included. The diagnosis of delayed or nonunion was made with history, physical examination, and radiographs or CT-scanning. Studies concerning
Table 2 Excluded articles with their exclusion reason

\begin{tabular}{|c|c|c|}
\hline Years & Author & Reason for exclusion \\
\hline 1969 & Werner & Case report \\
\hline 1972 & Esah & Case report \\
\hline 1975 & Kostuik & $\begin{array}{l}\text { Comparison of several } \\
\text { treatments }\end{array}$ \\
\hline 1984 & Müller & $\begin{array}{l}\text { Analysis bridgeplate, no } \\
\text { patient information }\end{array}$ \\
\hline 1985 & Slatis & 5 cases \\
\hline 1986 & Johnson & Double serie \\
\hline 1986 & Kreusch & Femur and tibia, mixed group \\
\hline 1986 & Klemm & Primary treatment \\
\hline 1990 & Wood & 5 cases \\
\hline 1990 & Blatter & Case report \\
\hline 1992 & Johnson & $\begin{array}{l}\text { Comparison of several } \\
\text { treatments }\end{array}$ \\
\hline 1992 & Hou & 5 cases \\
\hline 1997 & Wei & No nonunion \\
\hline 1998 & Ueng & 5 cases \\
\hline 1998 & Ueng & 5 cases \\
\hline 1998 & Johnson & Double serie \\
\hline 2000 & Giannoudis & No intervention \\
\hline 2000 & Kim & $\begin{array}{l}<5 \text { patients with femur } \\
\text { nonunion }\end{array}$ \\
\hline 2001 & Devnani & Location not mentioned \\
\hline 2001 & Bellabarba & Double serie \\
\hline 2002 & Ebraheim & Case report \\
\hline 2002 & Pihlajamäki & $\begin{array}{l}\text { Comparison of several } \\
\text { treatments }\end{array}$ \\
\hline 2002 & Menon & $\begin{array}{l}<5 \text { patients with femur } \\
\text { nonunion }\end{array}$ \\
\hline 2003 & Brinker & 5 cases \\
\hline 2003 & $\begin{array}{l}\text { Canadian Orthopaedic } \\
\text { Trauma Society }\end{array}$ & No nonunion \\
\hline 2003 & $\mathrm{Wu}$ & $\begin{array}{l}\text { Associated femoral neck } \\
\text { fracture }\end{array}$ \\
\hline 2007 & Crowley & Review \\
\hline 2007 & Alt & 1 case and double fracture \\
\hline 2007 & Morasiewicz & Femur and tibia, mixed group \\
\hline 2009 & Prasarn & 5 cases \\
\hline 2009 & Taitsman & No intervention \\
\hline 2010 & Wedemeyer & Case report \\
\hline 2011 & Wedemeyer & Case report \\
\hline 2011 & Kim & Classification \\
\hline
\end{tabular}


Table 3 Level of evidence

Level I: High-quality prospective randomized clinical trial

Level II: Prospective comparative study

Level III: Retrospective case control study

Level IV: Case series

Level V: Expert opinion

several types of nonunions were included if the femoral shaft nonunions could be evaluated separately.

Reports on nonunion after periprosthetic fractures were excluded. Review articles and expert opinions were excluded because these articles do not report on new patient series. Abstracts from scientific meetings that were not published as a full-text article were also excluded, as were case reports on 5 or less patients. The search was restricted to articles written in the English, German, and Dutch languages. Articles presenting data that were thought to have been presented previously were used once.

\section{Identification of studies}

A comprehensive literature search was performed with the assistance of a clinical librarian, using the following Mesh search terms: femur, nonunion, delayed union, pseudarthrosis, fracture, trauma, injury, healing, treatment, and complication (Table 1). The search was limited to adult humans in the following databases: PubMed/MEDLINE, Cochrane Clinical Trial Register, and EMBASE. Studies were searched in the period from January 1970 to March 2011. The obtained reference list of retrieved publications was manually checked for additional references potentially meeting the inclusion criteria and not found by the electronic search.

From the title abstract, two reviewers (MS and MB) independently reviewed the literature searches to identify relevant articles for full review. From the full text, using the above-mentioned criteria, the reviewers independently selected articles for inclusion in this review. Disagreement was resolved by group discussion, with arbitration by the senior author (PK) where differences remained. Studies were not blinded for author, affiliation, and source. Excluded articles are listed in Table 2.
Data extraction

After the initial assessment for inclusion, the following data were extracted from the included articles selected: (a) septic nonunion, type of initial and secondary treatments, follow-up, union rate, and general complications.

After initial data extraction, the exclusion criteria were reassessed. It became clear that most studies had different inclusion criteria and outcome measures, thus prohibiting a proper meta-analysis and comparison between the different studies. Only the union rate and number of complications were compared between the different treatments.

\section{Methodological quality}

Methodological quality of included studies was assessed by assigning levels of evidence as previously defined by the Centre for Evidence-Based Medicine (http://www.cebm. net). In short, for studies on therapy or prognosis, level I is attributed to well-designed and performed randomized controlled trials, level II to cohort studies, level III to case control studies, level IV to case series, and level $\mathrm{V}$ to expert opinion articles (Table 3). Levels of evidence were assigned by two authors (MS and MB). Disagreement was resolved by group discussion. Based on the levels of evidence, some recommendations for clinical practice were formulated. A grade was added, based on the evidence supporting that recommendation. Grade A meant treatment options were supported by strong evidence (consistent with level I or II studies); grade B meant treatment options were supported by fair evidence (consistent with level III or IV studies); grade $\mathrm{C}$ meant treatment options were supported by either conflicting or poor quality evidence (level IV studies); and grade D was used when insufficient evidence existed to make a recommendation (Table 4).

\section{Results}

Through database search, 71 articles were eligible for analysis. By manual reference checking, an additional 24 articles were included. After removal of 3 duplicates, 92 abstracts were screened. Ten articles were excluded based on the aforementioned criteria. The full text of the

Table 4 Grades of recommendation given to various treatment options based on the level of evidence

Evidence supporting that treatment

Grade A: Treatment options are supported by strong evidence (consistent with level I or II studies)

Grade B: Treatment options are supported by fair evidence (consistent with level III or IV studies)

Grade C: Treatment options are supported by either conflicting or poor quality evidence (level IV studies)

Grade D: Insufficient evidence exists to make a recommendation 


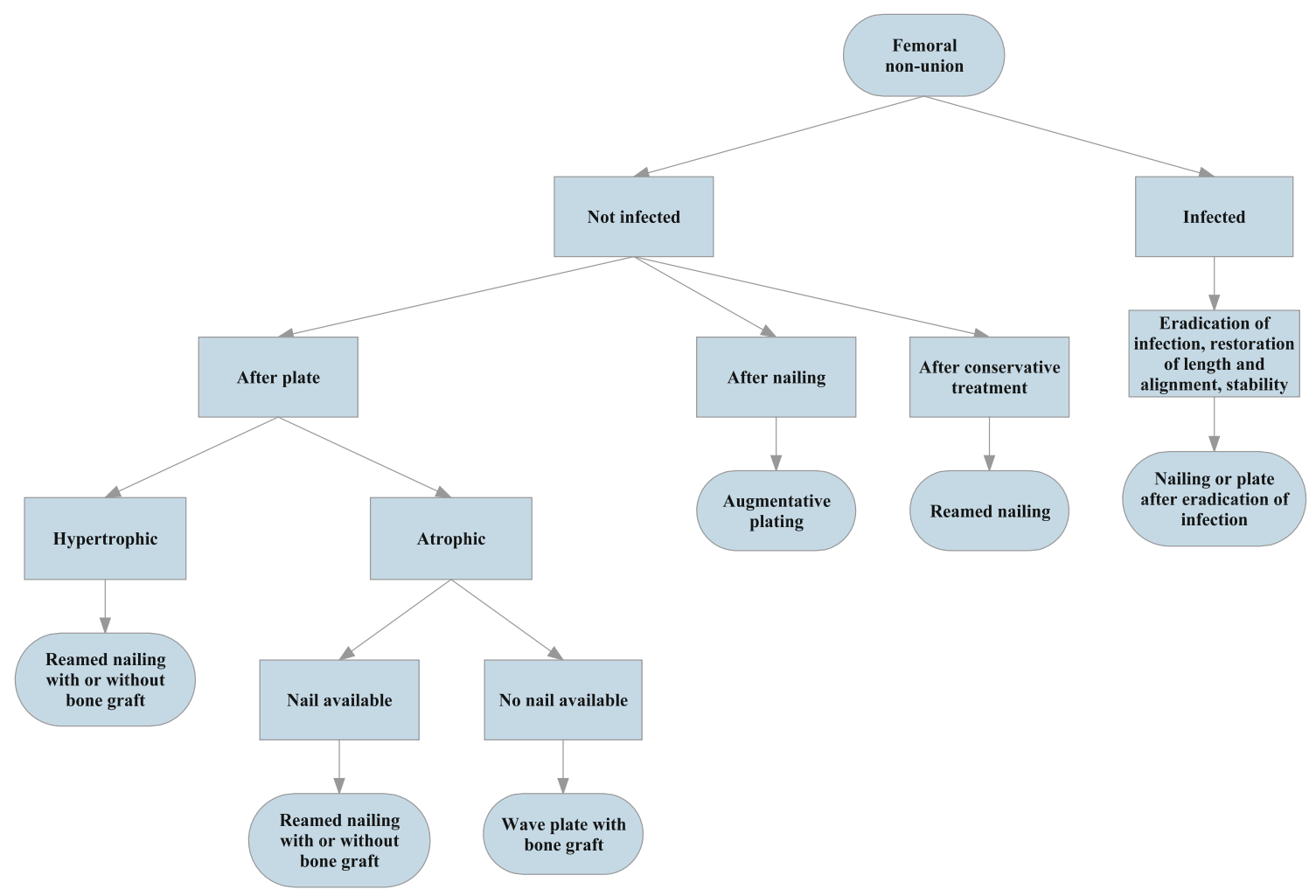

Fig. 1 Proposed decision chart for the treatment of femoral non-union

Table 5 Nailing after plate. Nonunions are not separately listed as complications

\begin{tabular}{|c|c|c|c|c|c|c|}
\hline Years & Author & Number of patients & Primary treatment & Secondary treatment & Complications & Union rate $\mathrm{n}(\%)$ \\
\hline 1999 & $\mathrm{Wu}$ & 21 & Plate & Reamed nail & Not mentioned & $21(100)$ \\
\hline 2001 & $\mathrm{Wu}$ & 8 & Plate & Nailing + bone graft & 0 & $7(93)$ \\
\hline 2008 & Emara* & 20 & Plate & Nailing + bone graft & 5 & $20(100)$ \\
\hline 2008 & Emara* & 20 & Plate & Nailing & 1 & $20(100)$ \\
\hline 2009 & Megas & 30 & Plate & Nailing & 8 & $27(91)$ \\
\hline \multicolumn{6}{|c|}{ Time to union (months) } & Remarks \\
\hline \multicolumn{7}{|l|}{6} \\
\hline \multicolumn{7}{|c|}{$4(3-6)$} \\
\hline \multicolumn{3}{|c|}{$4.8 \pm 1.15$} & & & & RCT \\
\hline \multicolumn{3}{|c|}{$4.9 \pm 1.33$} & & & & RCT \\
\hline \multicolumn{3}{|c|}{$7.9 \pm 3.3$} & & & & \\
\hline
\end{tabular}

* One study, divided in two groups to show the results of grafting or no grafting

remaining 82 articles was assessed. This resulted in an additional 25 articles being excluded because of the aforementioned criteria. Eventually, 57 articles were included in our analysis (Fig. 1).

The results of exchange nailing were described in 11 [6, 7] patient series concerning 343 patients with a union in
251 patients $(73 \%)$ and an average union time of 7 months. Six complications were described.

The results of augmentative plating were described in 5 studies concerning 121 patients with a union in 118 patients $(98 \%)$ and an average union time of 6 months. One complication was described. 
Table 6 Reports on exchange nailing. Nonunions are not separately listed as complications

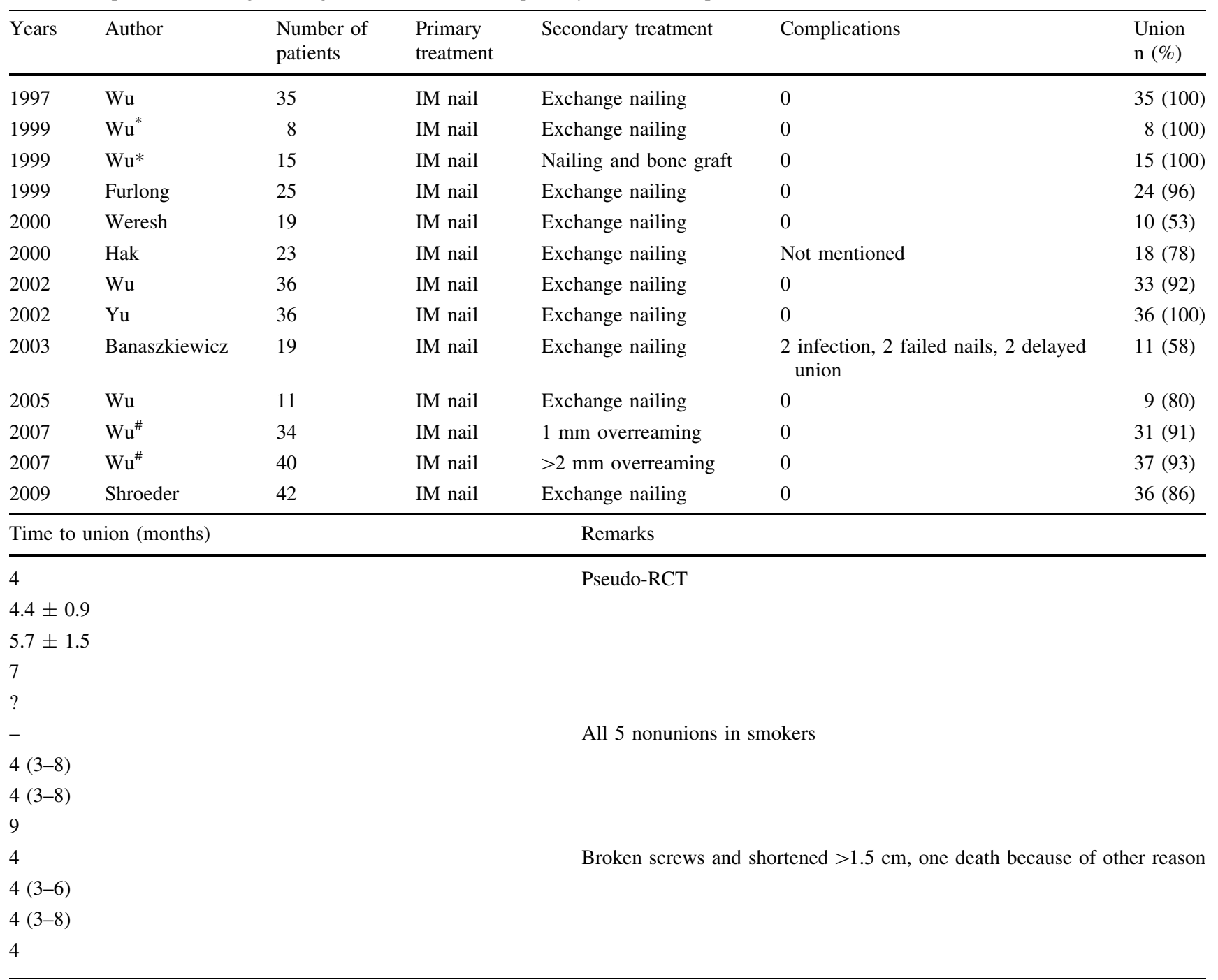

* One study, divided in two groups to show the results of grafting or no grafting

\# One study, divided in two groups to show the results of difference in the amount of overreaming

The results of nailing after initial plating were described in 5 patient series concerning 99 patients with a union in 95 patients $(96 \%)$ and an average union time of 6 months. Fourteen complications were described.

Thirty-four articles describe a technique that could not be classified in one the previous treatment categories (Fig. 1).

\section{Discussion}

Based on the systematic review of the currently available and relevant literature, we can formulate evidence-based guidelines for treatment of femoral shaft nonunions for clinical practice, as well as some recommendations for future research.

\section{Dynamization}

Dynamization is the removal of those interlocking screws that have initially statically locked an IM nail. This technique has been proven beneficial for example in tibial fracture healing [8]. However, the data remain conflicting with respect to the potential role of dynamization in femoral fracture healing $[9,10]$. To the best of our knowledge, no (randomized) comparative trial of dynamization alone versus other techniques has been performed. Auto-dynamization, the breakage of the screws of a statically locked 
Table 7 Reports on augmentative plating. Nonunions are not separately listed as complications

\begin{tabular}{llllllc}
\hline Years & Author & Number of patients & Primary treatment & Secondary treatment & Complications & Union rate $\mathrm{n}(\%)$ \\
\hline 1997 & Ueng & 17 & IM nail & Augmentative plate & Not mentioned & $17(100)$ \\
2005 & Choi & 15 & IM nail & Augmentative plating + bone graft & 0 & $15(100)$ \\
2008 & Nadkarni & 7 & IM nail & Augmentative plate & 0 & $7(100)$ \\
2008 & Roetman & 32 & IM nail & Augmentative plate & 0 & $29(91)$ \\
2010 & Chen & 50 & IM nail & Augmentative plating + bone graft & 1 & $50(100)$ \\
\hline
\end{tabular}

Time to union (months)

Remarks

$7(6-10)$

$7(5-11)$

$7(6-8)$

5

$6(4.5-8)$

8 distal and 7 proximal fractures

nail, has been described, but concerns only a subgroup of nonunions. Complications of dynamization include shortening of the affected limb.

\section{Recommendation grade D}

\section{Reamed nailing after plate}

Placing an IM nail after primary non-operative treatment was initially only used for midshaft femoral nonunions. The introduction of locking nails allowed reamed nailing to also be used for non-isthmal femoral nonunions.

A total of 99 patients from our systematic review were treated with a nail after primary plating distributed over 4 studies [11-14]. Average healing time was 6 months with a healing rate of $96 \%(n=95)$. Complications described were limited to nonunion after the secondary surgery. Emara et al. [13] did not find a difference in outcome if an additional autologous bone graft was used in a randomized trial (Table 5).

\section{Recommendation grade $\mathrm{C}$}

\section{Exchange reamed nailing}

If initial treatment with an IM nail results in a nonunion, the nail can be removed and a larger diameter nail can be placed after overreaming. The presumed causes of healing after exchange nailing are both biological and mechanical [5]. The biological effects believed to be that reaming increases periosteal blood flow, whereas it decreases endosteal vascularization. The periosteum reacts to increased blood flow with new bone formation. Products of the reaming itself contain osteoblasts and possibly multipotent stem cells as well as growth factors that play a role in bone healing.
The mechanical effects of reaming are that a larger diameter nail (preferably $>2 \mathrm{~mm}$ thicker) provides greater bending rigidity and strength than the original nail. Reaming also increases the length of the isthmus providing a better endosteal purchase of the new nail. Increased stability can also be obtained by placing a longer nail than before and by using a nail that allows for more interlocking holes and/or holes that are not parallel. Most recent advances are the option for locking nail implants that might provide increased stability.

In hypertrophic nonunions treated with exchange nailing, the increased stability will be sufficient for healing. For atrophic nonunions, it is thought that the reaming debris will augment bone healing. For nonunions treated with exchange nailing, there is a possible additional benefit from open bone grafting which might result in shorter union times [15].

Our systematic review resulted in 343 patients treated with exchange nailing in 11 studies [6, 7, 15-23]. Union was seen in $73 \%(n=251)$ at an average of 7 months. Of the complications reported, there were 2 failed nails and 2 infections. Of note is that recent studies have a lower success rate after reamed exchange nailing after one procedure than previous reports. We believe this is caused by the more liberal indications for reamed nailing and the type of nonunion (hypertrophic vs. atrophic) [24] (Table 6).

$\mathrm{Wu}$ et al. [22] published a retrospective comparison of reaming 1 or $>2 \mathrm{~mm}$ greater than the previous nail. This resulted in comparable union rates after a comparable time.

There is no consensus whether open bone grafting is beneficial in reamed exchange nailing for a nonunion. If residual instability is present, a locked augmentation plate can be placed [24, 25]. 


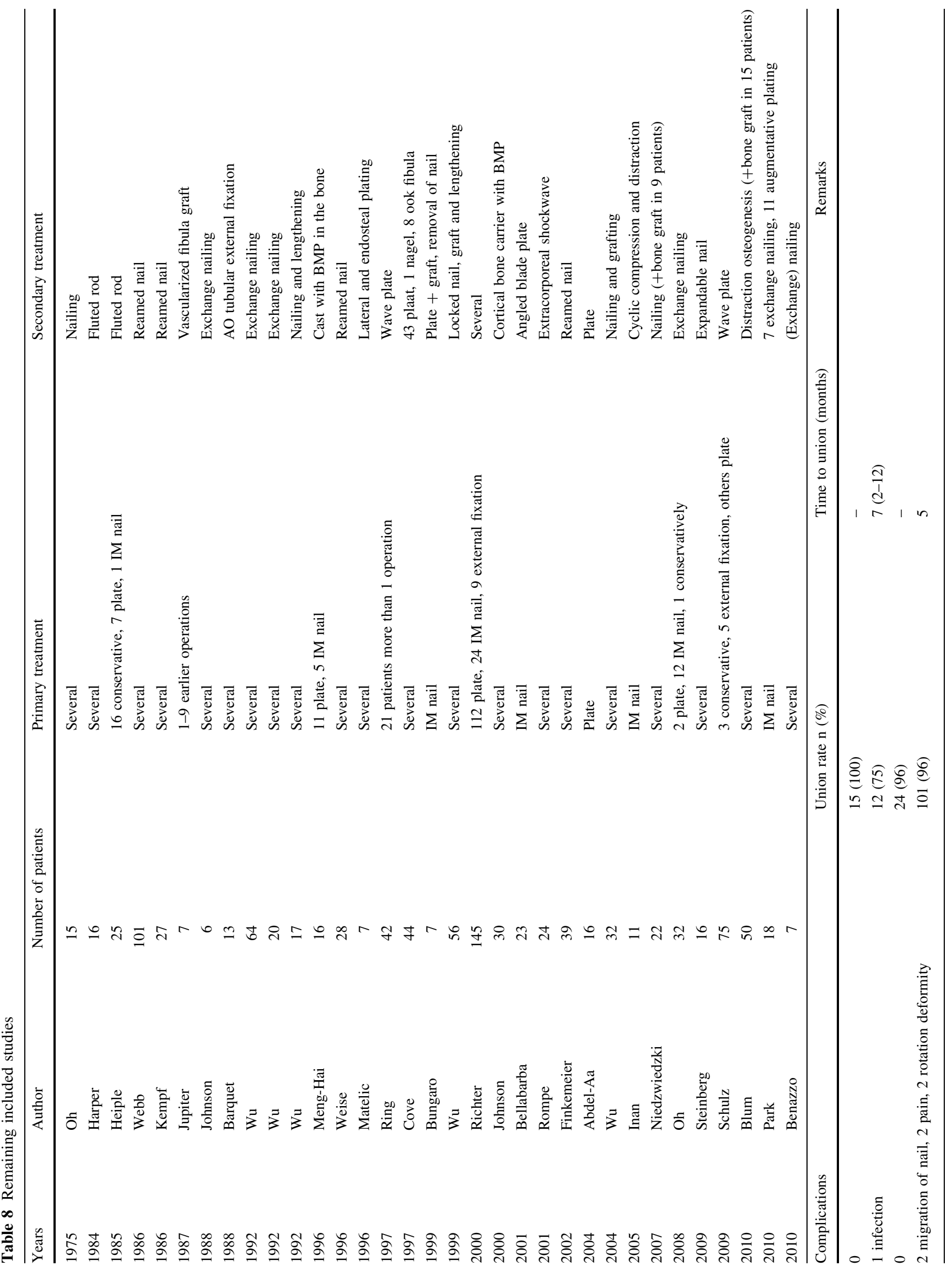




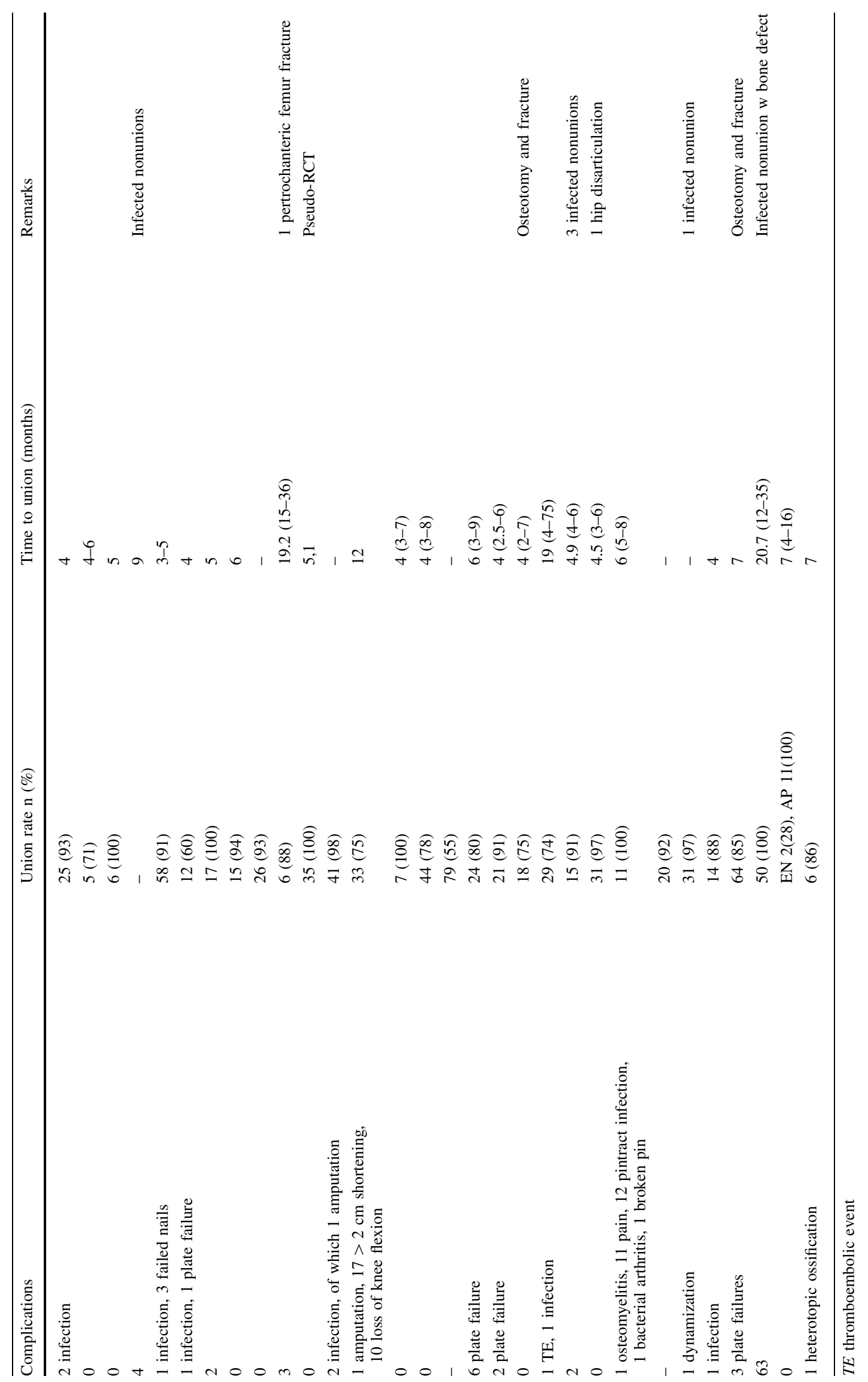




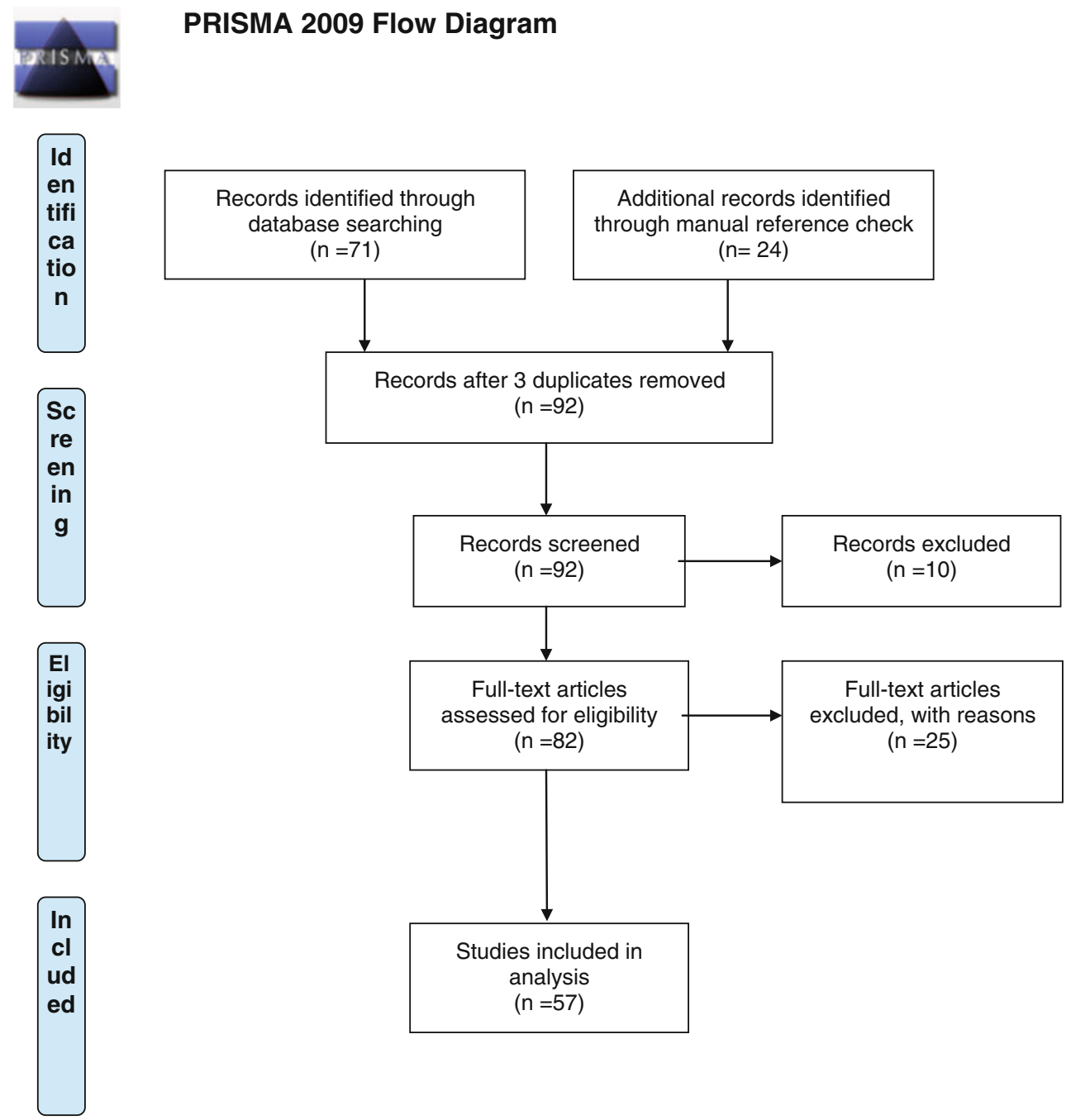

Fig. 2 PRISMA 2009 flow diagram. Source Moher et al. [62]

Recommendation grade $\mathrm{C}$

\section{Augmentative plate fixation}

Failure of exchange reamed nailing has been noted in nonunions with extensive comminution, large segmental defects, and metaphyseal-diaphyseal nonunions [18, 21]. Leaving the intramedullary nail in situ when plating a nonunion, i.e. augmentative plating, has been reported for humeral, tibial, and femoral nonunions [26]. This approach uses the load-sharing capacity of the nail with good axial and bending strength, while the plate provides additional rotational control. A retrospective study by Park et al. [27] showed, be it in small groups, that augmentative plating gave better outcomes than exchange nailing for non-isthmal femoral nonunions.
From our systemic review, we found 122 patients in 5 studies treated with augmentative plating [26, 28-31] $96 \%$ $(\mathrm{n}=118)$ healed in an average of 6 months. No complications were reported (Table 7).

Prior to the availability of locking plates (that can rely on unicortical fixation), this technique was quite challenging given the need for bicortical screw purchase. However, locking plates have substantially facilitated augmentative plating from a surgical technique perspective.

Removing the locking screws in the nail will even allow compression with the AO tensioner device prior to augmentative plating. Finally, the use of additional bone grafting in augmentative plate fixation is variable [16, 28-31].

An obvious shortcoming of this technique is that it does not allow for correction of deformity with the presence of an intact nail. 
Recommendation grade $\mathrm{C}$

\section{Plate fixation}

Before the introduction of reamed exchange nailing, the use of compression plating for femoral shaft nonunions was the gold standard. The plate functions as a tension band on the lateral side. As such, it will also help with correction of malalignment. The bone itself absorbs the axial compressive forces. In their book on nonunions, Weber and Čech [25] advocate debridement, sequestrectomy, use of plates for "mechanical rest" and "massive cancellous autograft".

In the recent AO book on nonunions, these are listed as still valid principles [32]. When there is a medial bony defect, a standard plate is subjected to a local concentration of bending forces which may induce failure. For these specific nonunions, the wave plate was introduced by Blatter and Weber [33]. The plate has a contour in its midportion so that it stands away from the bone at the abnormal area. The wave is believed to preserve local blood supply to the bone at the site of the nonunion and provides more space for grafting. The wave can share axial loads more effectively. Combined with the indirect reduction techniques using an $\mathrm{AO}$ femoral distractor, this technique can be considered "biological". In two large retrospective series of femoral shaft nonunions, the wave plate led to union after a single surgery in the vast majority of cases [e.g. 41 of 42 cases (98\% union rate) [34] and 64 of 75 cases ( $85 \%$ union rate) [35]]. Schulz et al. also included nonunions after osteotomies. The complications reported were 2 infections and 9 nonunions.

\section{Recommendation grade $\mathrm{C}$}

\section{Remaining papers}

Only scarce literature exists on the treatment of infected femoral shaft nonunions. In general, the treatment goals for these nonunions are: eradication of infection, restoration of length and alignment, bone healing, and optimal functional outcome [36].

There remained a considerable amount of other treatments, obsolete treatments, or reports which were too heterogeneous to draw conclusions from [24, 37-61] (Table 8).

\section{Conclusions}

Care should be taken in interpreting these results since the overall grade of recommendation did not exceed grade $\mathrm{C}$, meaning weak support of the drawn conclusions. However, based on the best available evidence, we conclude that augmentative plating is the treatment of choice if an intramedullary nail is in situ (augmentative plating results in a $96 \%$ union rate compared to $73 \%$ in the exchange nailing group). The concept is that nonunion after nailing is in a great part of cases because of instability (hypertrophic nonunion) which is treated with providing stability. This is easier to achieve with an augmentative plate than with exchange nailing.

In case of a failed plate fixation, reamed nailing results in $96 \%$ union rate, thus being the treatment of choice. If a plate is the only available treatment option, a wave plate should be placed to preserve blood supply at the nonunion site and to share the axial load as good as possible.

With the recommendations from our review, we propose a decision diagram for treating femoral nonunions. Where no evidence is present we included our own experiences (Fig. 2).

Acknowledgments The authors are grateful to Hanny Vriends for her help with the systematic search and collecting the required articles.

Conflict of interest The authors declare that they have no conflict of interest.

Open Access This article is distributed under the terms of the Creative Commons Attribution License which permits any use, distribution, and reproduction in any medium, provided the original author(s) and the source are credited.

\section{References}

1. Küntscher G, Maatz R (1945) Technik der Marknagelung. Georg Thieme Verlag, Leipzig

2. Böhler L (1943) Vorschlag zur Marknagelung nach Küntscher bei frischen Oberschenkelschussbrüchen. Der Chirurg 15-1:8-13

3. Canadian Orthopaedic Trauma Society (2003) Non-union following intramedullary nailing of the femur with and without reaming. Results of a multicenter randomized clinical trial. J Bone Joint Surg Am 85A(11):2093-2096

4. Attal R, Blauth M (2010) Unreamed intramedullary nailing. Orthopade 39-2:182-191

5. Brinker MR (2003) Skeletal trauma: basic science management, and reconstruction, 3 edn. Saunders, Philadelphia

6. Yu CW, Wu CC, Chen WJ (2002) Aseptic non-union of a femoral shaft treated using exchange nailing. Chang Gung Med J 25-9:591-598

7. Shroeder JE, Mosheiff R, Khoury A et al (2009) The outcome of closed, intramedullary exchange nailing with reamed insertion in the treatment of femoral shaft non-unions. J Orthop Trauma 23-9:653-657

8. Richardson JB, Gardner TN, Hardy JR et al (1995) Dynamisation of tibial fractures. J Bone Joint Surg Br 77-3:412-416

9. Wu CC, Lee ZL (2005) Low success rate of non-intervention after breakage of interlocking nails. Int Orthop 29-2:105-108

10. Pihlajamaki HK, Salminen ST, Bostman OM (2002) The treatment of non-unions following intramedullary nailing of femoral shaft fractures. J Orthop Trauma 16-6:394-402 
11. Wu CC, Shih CH, Chen WJ et al (1999) Effect of reaming bone grafting on treating femoral shaft aseptic non-union after plating. Arch Orthop Trauma Surg 119:303-307

12. Wu CC (2001) Treatment of femoral shaft aseptic non-union associated with plating failure: emphasis on the situation of screw breakage. J Trauma 51-4:710-713

13. Emara KM, Allam MF (2008) Intramedullary fixation of failed plated femoral diaphyseal fractures: are bone grafts necessary? J Trauma 65-3:692-697

14. Megas P, Syggelos SA, Kontakis G et al (2009) Intramedullary nailing for the treatment of aseptic femoral shaft non-unions after plating failure: effectiveness and timing. Injury 40-7:732-737

15. Furlong AJ, Giannoudis PV, DeBoer P et al (1999) Exchange nailing for femoral shaft aseptic non-union. Injury 30-4:245-249

16. Wu CC, Chen WJ (1997) Treatment of femoral shaft aseptic nonunions: comparison between closed and open bone-grafting techniques. J Trauma 43-1:112-116

17. Wu CC, Shih CH, Chen WJ et al (1999) Treatment of ununited femoral shaft fractures associated with locked nail breakage: comparison between closed and open revision techniques. J Orthop Trauma 13-7:494-500

18. Weresh MJ, Hakanson R, Stover MD et al (2000) Failure of exchange reamed intramedullary nails for ununited femoral shaft fractures. J Orthop Trauma 14-5:335-338

19. Hak DJ, Lee SS, Goulet JA (2000) Success of exchange reamed intramedullary nailing for femoral shaft non-union or delayed union. J Orthop Trauma 14-3:178-182

20. Wu CC, Chen WJ (2002) Exchange nailing for aseptic non-union of the femoral shaft. Int Orthop 26-2:80-84

21. Banaszkiewicz PA, Sabboubeh A, McLeod I et al (2003) Femoral exchange nailing for aseptic non-union: not the end to all problems. Injury 34-5:349-356

22. Wu CC (2007) Exchange nailing for aseptic non-union of femoral shaft: a retrospective cohort study for effect of reaming size. J Trauma 63-4:859-865

23. Wu CC, Lee ZL (2005) Treatment of femoral shaft aseptic nonunion associated with broken distal locked screws and shortening. J Trauma 58-4:837-840

24. Finkemeier CG, Chapman MW (2002) Treatment of femoral diaphyseal non-unions. Clin Orthop Relat Res 398:223-234

25. Weber BG, Čech O (1973) Pseudarthrosen. Hans Huber, Bern

26. Nadkarni B, Srivastav S, Mittal V et al (2008) Use of locking compression plates for long bone non-unions without removing existing intramedullary nail: review of literature and our experience. J Trauma 65-2:482-486

27. Park J, Kim SG, Yoon HK et al (2010) The treatment of nonisthmal femoral shaft non-unions with im nail exchange versus augmentation plating. J Orthop Trauma 24-2:89-94

28. Ueng SW, Chao EK, Lee SS et al (1997) Augmentative plate fixation for the management of femoral non-union after intramedullary nailing. J Trauma 43-4:640-644

29. Choi YS, Kim KS (2005) Plate augmentation leaving the nail in situ and bone grafting for non-union of femoral shaft fractures. Int Orthop 29-5:287-290

30. Roetman B, Scholz N, Muhr G et al (2008) Augmentive plate fixation in femoral non-unions after intramedullary nailing. Strategy after unsuccessful intramedullary nailing of the femur. Z Orthop Unfall 146-5:586-590

31. Chen CM, Su YP, Hung SH et al (2010) Dynamic compression plate and cancellous bone graft for aseptic non-union after intramedullary nailing of femoral fracture. Orthopedics 33-6:393

32. Marti RK, Kloen P (2011) Concepts and cases in non-union treatment, 1st edn. Georg Thieme Verlag, Stuttgart, pp 20-150

33. Blatter G, Weber BG (1990) Wave plate osteosynthesis as a salvage procedure. Arch Orthop Trauma Surg 109-6:330-333
34. Ring D, Jupiter JB, Sanders RA et al (1997) Complex non-union of fractures of the femoral shaft treated by wave-plate osteosynthesis. J Bone Joint Surg Br 79-2:289-294

35. Schulz AP, Faschingbauer M, Seide K et al (2009) Is the wave plate still a salvage procedure for femoral non-union? Results of 75 cases treated with a locked wave plate. Eur J Trauma Emerg Surg 35-2:127-131

36. Prasarn ML, Ahn J, Achor T et al (2009) Management of infected femoral non-unions with a single-staged protocol utilizing internal fixation. Injury 40-11:1220-1225

37. Cove JA, Lhowe DW, Jupiter JB et al (1997) The management of femoral diaphyseal non-unions. J Orthop Trauma 11-7:513520

38. Oh I, Nahigian SH, Rascher JJ et al (1975) Closed intramedullary nailing for ununited femoral shaft fractures. Clin Orthop Relat Res 106:206-215

39. Harper MC (1984) Ununited fractures of the femur stabilized with the fluted rod. Clin Orthop Relat Res 190:273-278

40. Heiple KG, Figgie HE 3rd, Lacey SH et al (1985) Femoral shaft non-union treated by a fluted intramedullary rod. Clin Orthop Relat Res 194:218-225

41. Webb LX, Winquist RA, Hansen ST (1986) Intramedullary nailing and reaming for delayed union or non-union of the femoral shaft. A report of 105 consecutive cases. Clin Orthop Relat Res 212:133-141

42. Kempf I, Grosse A, Rigaut P (1986) The treatment of noninfected pseudarthrosis of the femur and tibia with locked intramedullary nailing. Clin Orthop Relat Res 212:142-154

43. Jupiter JB, Bour CJ, May JW Jr (1987) The reconstruction of defects in the femoral shaft with vascularized transfers of fibular bone. J Bone Joint Surg Am 69(3):365-374

44. Johnson EE (1988) Custom titanium plating for failed non-union or delayed internal fixation of femoral fractures. Clin Orthop Relat Res 234:195-203

45. Barquet A, Silva R, Massaferro J et al (1988) The AO tubular external fixator in the treatment of open fractures and infected non-unions of the shaft of the femur. Injury 19(6):415-420

46. Wu CC, Shih CH (1992) Treatment of 84 cases of femoral nonunion. Acta Orthop Scand 63(1):57-60

47. Wu CC, Shih CH, Lee ZL (1992) A simpler surgical technique to treat aseptic non-union-associated femoral length discrepancy. Arch Orthop Trauma Surg 111(3):160-164

48. Meng-Hai MH, Liu XY, Ge BF et al (1996) An implant of a composite of bovine bone morphogenetic protein and plaster of paris for treatment of femoral shaft non-unions. Int Surg 81(4):390-392

49. Weise K, Winter E (1996) Role of intramedullary nailing in pseudarthrosis and malalignment. Orthopade 25(3):247-258

50. Matelic TM, Monroe MT, Mast JW (1996) The use of endosteal substitution in the treatment of recalcitrant non-unions of the femur: report of seven cases. J Orthop Trauma 10(1): $1-6$

51. Bungaro P, Pascarella R, Colozza A et al (1999) Rigid fixation with plate and bone graft in failures of intramedullary osteosynthesis for the treatment of diaphyseal non-union of the femur. Chir Organi Mov 84(3):263-267

52. Bellabarba C, Ricci WM, Bolhofner BR (2001) Results of indirect reduction and plating of femoral shaft non-unions after intramedullary nailing. J Orthop Trauma 15(4):254-263

53. Rompe JD, Rosendahl T, Schollner C et al (2001) High-energy extracorporeal shock wave treatment of non-unions. Clin Orthop Relat Res 387:102-111

54. Abdel-Aa AM, Farouk OA, Elsayed A et al (2004) The use of a locked plate in the treatment of ununited femoral shaft fractures. J Trauma 57(4):832-836 
55. Wu CC, Lee ZL (2004) One-stage lengthening using a locked nailing technique for distal femoral shaft non-unions associated with shortening. J Orthop Trauma 18(2):75-80

56. Inan M, Karaoglu S, Cilli F et al (2005) Treatment of femoral non-unions by using cyclic compression and distraction. Clin Orthop Relat Res 436:222-228

57. Niedzwiedzki T, Brudnicki J, Niedzwiedzki L (2007) Treatment of femoral shaft union disturbances with intramedullary nailing. Treatment failure. Ortop Traumatol Rehabil 9(4):377-383

58. Oh JK, Bae JH, Oh CW et al (2008) Treatment of femoral and tibial diaphyseal non-unions using reamed intramedullary nailing without bone graft. Injury 39(8):952-959
59. Steinberg EL, Keynan O, Sternheim A et al (2009) Treatment of diaphyseal non-union of the femur and tibia using an expandable nailing system. Injury 40(3):309-314

60. Benazzo F, Mosconi M, Bove F et al (2010) Treatment of femoral diaphyseal non-unions: our experience. Injury 41(11):1156-1160

61. Richter J, Schulze W, Muhr G (2000) Diaphyseal femur pseudarthroses-only a technical problem? Chirurg 71(9):1098-1106

62. Moher D, Liberati A, Tetzlaff J, Altman DG, The PRISMA Group (2009) Preferred reporting items for systematic reviews and meta-analyses: the PRISMA statement. PLoS Med 6(6):e1000097. doi:10.1371/journal.pmed1000097 